\title{
Pharmacokinetic and Pharmacodynamic Studies of Elacestrant, A Novel Oral Selective Estrogen Receptor Degrader, in Healthy Post-Menopausal Women
}

\author{
Maureen G. Conlan ${ }^{1}$ (D . Erik F. J. de Vries $^{2} \cdot$ AWJM Glaudemans $^{2} \cdot$ Yamei Wang $^{3} \cdot$ Steven Troy $^{4}$
}

Published online: 13 July 2020

(c) The Author(s) 2020, corrected publication 2020

\begin{abstract}
Background and Objectives Advanced estrogen receptor-positive (ER+) breast cancer is currently treated with endocrine therapy. Elacestrant is a novel, nonsteroidal, selective estrogen receptor degrader with complex dose-related ER agonist/ antagonist activity that is being developed as a treatment option for ER+ breast cancer.

Methods Two first-in-human phase 1 studies of elacestrant in healthy postmenopausal women (Study 001/Study 004) were conducted to determine its pharmacokinetic and pharmacodynamic profile as well as its safety and maximum tolerated dose. Results In total, 140 postmenopausal subjects received at least one dose of study drug (114 received elacestrant and 26 received placebo). Single-ascending dose and multiple-ascending dose assessments showed that doses up to $1000 \mathrm{mg}$ daily were safe and well tolerated, and the maximum tolerated dose was not reached. Oral administration of elacestrant had an absolute bioavailability of $10 \%$ and a mean half-life ranging from 27 to $47 \mathrm{~h}$, reaching steady state after 5-6 days. Mean occupancy of the ER in the uterus after seven daily doses was $83 \%$ for $200 \mathrm{mg}$ and $92 \%$ for $500 \mathrm{mg}$ daily. The median ratio of elacestrant concentrations in the cerebral spinal fluid vs. plasma was $0.126 \%$ (500 mg dose) and $0.205 \%$ (200 $\mathrm{mg}$ dose). Most adverse events were related to the upper gastrointestinal tract.

Conclusions These data demonstrate that elacestrant has good bioavailability when administered orally with a half-life that supports once-daily administration. Engagement of the ER and some ability to cross the blood-brain barrier was demonstrated in addition to an acceptable safety profile.
\end{abstract}

Electronic supplementary material The online version of this article (https://doi.org/10.1007/s13318-020-00635-3) contains supplementary material, which is available to authorized users.

Maureen G. Conlan

mconlan@radiuspharm.com

1 Department of Oncology Clinical Development, Radius Health, Inc., 950 Winter Street, Waltham, MA 02451, USA

2 Department of Nuclear Medicine and Molecular Imaging, University Medical Center Groningen, University of Groningen, Hanzeplein 1, 9713 GZ Groningen, The Netherlands

3 Department of Biostatistics, Radius Health, Inc., 950 Winter Street, Waltham, MA, USA

4 Department of Clinical Pharmacology, Radius Health, Inc., 950 Winter Street, Waltham, MA, USA

\section{Key Points}

Elacestrant, an oral SERD, is safe and well tolerated at oral doses up to $500 \mathrm{mg}$ per day

Robust ER $\alpha$ occupancy (75-90\%) is observed at elacestrant doses of $200 \mathrm{mg}$ to $500 \mathrm{mg}$ daily

Elacestrant's bioavailability and long $t_{1 / 2}$ support a oncedaily oral dosing

\section{Introduction}

Breast cancer continues to be the most commonly diagnosed malignancy among women [1], and approximately $75 \%$ of all breast cancers are estrogen receptor-positive and human 
epidermal growth factor type-2-negative (ER+/HER2-) [2]. For patients with ER+/HER2- advanced or metastatic breast cancer (MBC), endocrine therapies such as aromatase inhibitors, selective ER modulators and selective ER degraders (SERDs) remain the cornerstone of treatment [3]. One of the most commonly used and effective endocrine therapies is fulvestrant. Fulvestrant is the only SERD currently approved for MBC in postmenopausal women [4] and has demonstrated therapeutic efficacy as monotherapy and in combination with targeted therapies, such as CDK4/6 inhibitors [5-9]. However, fulvestrant is limited by its poor oral bioavailability and the requirement for intramuscular injection [4].

Elacestrant is a novel nonsteroidal SERD [10] that has activity against ER+ breast cancer in both in vitro and in vivo models, including xenografts derived from heavily pretreated patients [11-13]. Importantly, elacestrant has antitumor activity in models resistant to fulvestrant and CDK4/6 inhibitors, including those harboring ESR1 Y537S and D538F mutations [11, 14-16]. In a phase 1 trial, single-agent oral elacestrant $400 \mathrm{mg}$ daily showed an overall response rate of $19.4 \%$ and a median progression-free survival of 4.5 months in 50 heavily pretreated patients with ER+/HER2- MBC. Subjects in this trial had a median of three prior lines of therapy, including $52 \%$ with prior CDK4/6 inhibitors and 50\% with prior fulvestrant, and 51\% had tumors that harbored ESRI mutations [17].

The pharmacokinetics, pharmacodynamic profile, oral bioavailability, and maximum tolerated dose (MTD) of elacestrant in healthy postmenopausal women have not been reported yet. We summarize the results from two first-inhuman phase 1 studies that were undertaken to characterize the pharmacokinetic characteristics (including oral bioavailability and food effect), pharmacodynamic profile (ER $\alpha$ occupancy), safety and tolerability and to establish the MTD of elacestrant in healthy postmenopausal women volunteers to guide dose selection in the clinical development of elacestrant in ER+/HER- MBC.

\section{Methods}

\subsection{Study Design}

Two phase 1, randomized, placebo-controlled studies (Study 001 [EudraCT number: 2007-006547-41] and Study 004 [EudraCT number: 2014-001699-67]) were conducted in healthy postmenopausal women. Both studies were conducted with the capsule formulation of elacestrant, which has since been replaced with a tablet formulation in all ongoing trials.

Study 001 consisted of a single ascending dose (SAD) component (single oral doses of 1-200 mg) and a multiple ascending dose (MAD) component (oral 10-200 mg daily for 7 days). Study 001 also examined the oral bioavailability of elacestrant and potential food effect. Treatment groups are shown in Fig. 1. The starting oral dose of $1 \mathrm{mg}$ was selected based on preclinical animal and toxicology studies.

Study 004 was a dose-escalation study designed to assess the MTD of elacestrant at oral doses of 200-1000 mg once daily for 7 days. The planned treatment groups are shown in Fig. 2. In addition to safety and pharmacokinetics, this study included a cohort to determine the pharmacodynamic parameter of ER $\alpha$ occupancy in the uterus and pituitary as determined by $16 \alpha-\left[{ }^{18} \mathrm{~F}\right.$ - $]$ fluoroestradiol (FES) positron emission tomography (PET) imaging and lumbar puncture to obtain cerebrospinal fluid (CSF) to determine elacestrant's blood-brain barrier (BBB) penetration and CSF concentrations. The starting dose of $200 \mathrm{mg}$ once daily for 7 days was based on the tested maximum single and repeated daily dose in Study 001. The dose-escalation components of both studies used a standard ascending dose tolerance design where investigators and the sponsor evaluated safety and tolerability following the completion of each dose cohort.

The clinical study protocols and informed consent forms were reviewed and approved by an independent ethics committee, and all subjects provided written informed consent. Both studies were conducted in accordance with the principles of the Declaration of Helsinki and in compliance with the International Conference on Harmonisation (ICH) E6 Guideline for Good Clinical Practice (GCP) (Committee for Proprietary Medicinal Products (CPMP) guideline CPMP/ ICH/135/95) and with the EU CTD: Directive 2001/20/EC.

\subsection{Procedures}

Screening took place within 30 days before the first administration of study drug in both studies. The main inclusion criteria included age 40-75 years, body mass index (BMI) $18-30 \mathrm{~kg} / \mathrm{m}^{2}$, postmenopausal status defined as $\geq 12$ months of amenorrhea and FSH concentrations within the postmenopausal range. Key exclusion criteria included a history of significant medical conditions, pregnancy or lactation, use of any concomitant medications except acetaminophen within 14 days of study drug administration, and smoking or use of any tobacco products within 60 days of study drug administration.

In the SAD part of Study 001, subjects were enrolled into one of four cohorts and randomized to receive a single dose of elacestrant (1-200 mg) or placebo in oral capsules in each of two study periods. Cohorts 1 and 2 received two different oral doses of elacestrant in the fasted state in the two periods (Fig. 1). Cohort 3 evaluated the same oral dose $(50 \mathrm{mg}$ ) in both periods, one under fasted and the other under fed conditions. Cohort 4 received $100 \mathrm{mg}$ fasted oral dose in the first period and $1 \mathrm{mg}$ intravenous dose in the second 


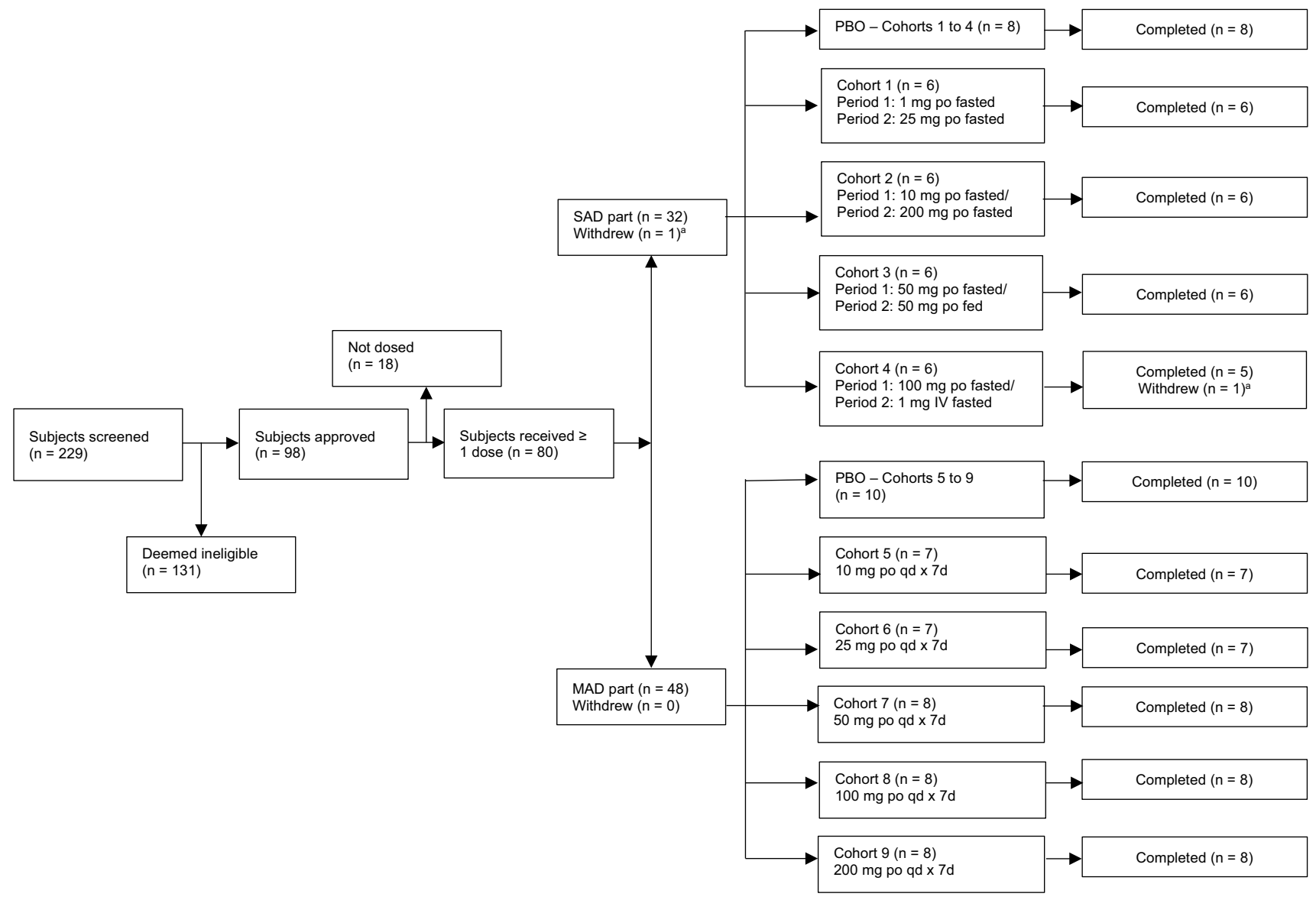

Fig. 1 Subject disposition in Study 001. a Subject withdrew informed consent after period 1; $I V$ intravenous, $M A D$ multiple ascending dose, $P B O$ placebo, po orally, $q d$ once daily, $S A D$ single ascending dose

period. The washout between the two study periods was at least 1 week. Both study periods included pharmacokinetic assessments for $72 \mathrm{~h}$ after study drug administration, after which participants were discharged on the 4th day. In the MAD part, subjects were enrolled in one of five cohorts and randomized to receive oral doses of elacestrant $10-200 \mathrm{mg}$ daily or placebo for 7 days, and the pharmacokinetic profile was assessed for $24 \mathrm{~h}$ after the day 1 dose and for $48 \mathrm{~h}$ following the last dose on day 7. Subjects were discharged on the morning of the 10th day. All patients in Study 001 had a follow-up visit 7-10 days after their discharge.

In all of the SAD and MAD cohorts in Study 001, except for period 2 of Cohort 3, oral elacestrant was administered between 9 and $10 \mathrm{~h}$ after a 10-h fast. Participants remained fasted until $4 \mathrm{~h}$ after drug administration. In period 2 of the SAD part of Cohort 3, which evaluated the food effect on pharmacokinetic parameters, elacestrant was administered after a high-fat breakfast per the Food and Drug Administration (FDA) industry guidelines [18].

In Study 004, Cohorts 1 through 5 were designed to evaluate the MTD of elacestrant while Cohort 6 assessed its ER $\alpha$ occupancy and BBB penetration. The elacestrant dose in Cohort 5 was not predefined but was to be based on an interim analysis of elacestrant exposure by dose relative to the incidence of treatment-emergent adverse events (TEAEs) in Cohorts 1 through 4 as well as ER $\alpha$ occupancy data in Cohort 6. In Cohorts 1 through 4, subjects were randomized to receive 200 to $1000 \mathrm{mg}$ elacestrant or placebo (Fig. 2). For all cohorts, elacestrant was administered as oral capsules in the fed state, following a light meal, once daily for 7 days. The assigned elacestrant dose was achieved by a combination of either $100 \mathrm{mg}$ or $150 \mathrm{mg}$ capsules: $200 \mathrm{mg}$ ( $2 \times 100 \mathrm{mg}$ capsules), $500 \mathrm{mg}(2 \times 100 \mathrm{mg}$ capsules plus $2 \times 150 \mathrm{mg}$ capsules $), 750 \mathrm{mg}(5 \times 150 \mathrm{mg}$ capsules $)$ or $1000 \mathrm{mg}(1 \times 100 \mathrm{mg}$ capsule plus $6 \times 150 \mathrm{mg}$ capsules $)$. Pharmacokinetic plasma concentrations were assessed over $24 \mathrm{~h}$ and then at 48, 72, 96, 144 and $192 \mathrm{~h}$ post-dose on day 7. Trough concentrations were sampled pre-dose on days 5 and 6. Samples were also obtained at outpatient follow-up visits on days $11,13,15$ and day $19 \pm 2$.

In Study 004 Cohort 6, subjects received oral 200 or $500 \mathrm{mg}$ elacestrant capsules daily for 7 days without randomization to placebo and underwent lumbar puncture $2-4 \mathrm{~h}$ after dosing on day 7 , corresponding to the observed $t_{\max }$ in 

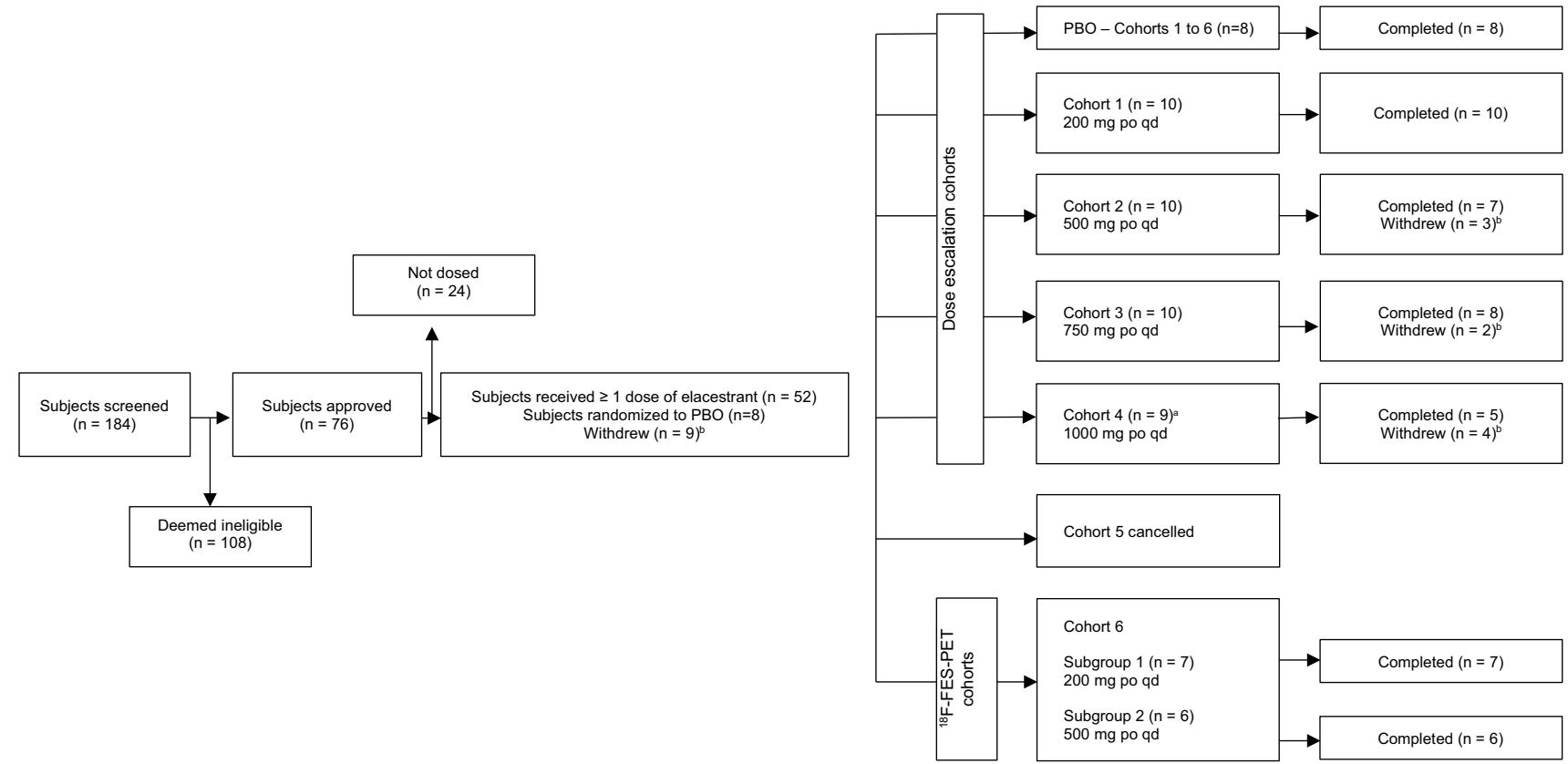

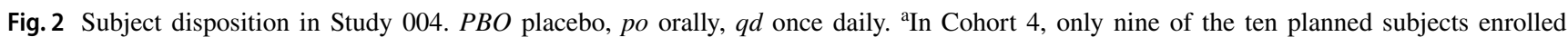
because of logistical considerations. All withdrawals from the study were due to adverse events

Study 001 (mean $t_{\max }$ ranged from 1.64 to $3.93 \mathrm{~h}$, Table 2) to determine elacestrant concentrations in the CSF. The plasma sample corresponding to the CSF sampling time point was obtained immediately after the lumbar puncture procedure. As the study was originally designed, subjects in Cohort 6 were to be assessed with dynamic and static ${ }^{18}$ F-FES-PET imaging to determine ER $\alpha$ occupancy in the brain (in particular, the pituitary) and uterus, respectively. The tracer ${ }^{18} \mathrm{~F}$-FES was produced according to a previously described method [19]. On day -1 and $4 \mathrm{~h}$ after oral intake of elacestrant on day $6,{ }^{18} \mathrm{~F}$-FES $(200 \mathrm{MBq})$ was administered intravenously, and a 90-min dynamic PET scan of the brain was performed immediately after tracer administration. During the dynamic PET scan, arterial blood sampling was performed to generate a plasma radioactivity input curve to enable pharmacokinetic modeling of the PET data. The plasma curve was corrected for the presence of radioactive metabolites of the tracer, as determined by thin-layer chromatography analysis [20]. Immediately after completion of the dynamic scan of the brain, a 5-min static PET scan of the uterus was started. The scans included a low-dose computed tomography (CT) of the brain and the uterus to correct for attenuation and scatter of radioactivity.

As a result of emerging data from Cohort 6 showing limited ER $\alpha$ occupancy in the brain (with the exception of pituitary) and low elacestrant concentrations in the CSF, the dynamic PET scan was eliminated, and the remaining subjects in Cohort 6 only underwent a 5-min static PET scan of the uterus and the brain 90 min after tracer injection on day -1 and day 6 .

Based on the ER $\alpha$ occupancy data at $200 \mathrm{mg}$ and $500 \mathrm{mg}$ in Cohort 6, as well as an interim analysis of elacestrant exposure by dose relative to the incidence of treatmentemergent adverse events (TEAEs) in Cohorts 1 to 4, it was determined that doses $>1000 \mathrm{mg}$ daily were unlikely to be pursued in future studies. Hence, Cohort 5 was eliminated.

Adverse events, vital signs, ECGs and laboratory tests were monitored throughout both studies to assess the safety and tolerability of elacestrant or placebo.

Concentrations of elacestrant in plasma, urine and cerebrospinal fluid (CSF) were determined with validated liquid chromatography with tandem mass spectrometry detection (Sciex 5000 mass spectrometer coupled with an Acquity UPLC system) (LC-MS/MS) methods at PRA Health Sciences Bioanalytical Laboratory (Assen, The Netherlands). Characteristic ion dissociation transitions were $\mathrm{m} / \mathrm{z}$ $459.35 \rightarrow 268.15$ for elacestrant and $463.35 \rightarrow 272.23$ for the internal standard (deuterated elacestrant-d4). Assessments were conducted via Acquity UPLC BEH Shield RP18 column $(50 \times 2.1 \mathrm{~mm}, 1.7 \mu \mathrm{m})$ (Waters Corp., Milford, MA, USA) with a blended mobile phase of acetonitrile and $0.1 \%$ formic acid in water using a varying gradient program. Flow rate was $0.8 \mathrm{ml} / \mathrm{min}$. The assay was validated for specificity, precession, accuracy, sensitivity, stability and linearity over a concentration range of $0.05-100 \mathrm{ng} / \mathrm{ml}$ in all matrices. Samples were prepared using a liquid-liquid extraction procedure as follows: $300 \mu \mathrm{l} 1 \%$ formic acid in water was added 
to $150 \mu \mathrm{l}$ plasma, vortex-mixed for $10 \mathrm{~s}$ then transferred to a well of a SPE plate, which had been conditioned with 200 $\mu \mathrm{l}$ methanol and $200 \mu \mathrm{l} 1 \%$ formic acid in water. After washing with $200 \mu \mathrm{l} 1 \%$ formic acid in water and $200 \mu \mathrm{l}$ methanol, the SPE-plate was eluted with $100 \mu$ l elution solvent (acetonitrile: methanol: ammonia [25\%] [49:49:2, v/v/v]) into deep-well polypropylene collection plates. The sample was evaporated to dryness under nitrogen at approximately $60{ }^{\circ} \mathrm{C}$ at a gas flow of ca. $40 \mathrm{CFH}$ in $10 \mathrm{~min}$, and the residue was redissolved in $200 \mu \mathrm{l}$ reconstitution solvent (acetonitrile: water: formic acid [20:80:0.2, v/v/v]) by vortex mixing for $1 \mathrm{~min}$, and an aliquot of $5 \mu \mathrm{l}$ was injected into the chromatographic system. All analytical runs were performed with QC samples of $0.15,7.5$, and $80 \mathrm{ng} / \mathrm{ml}$, and the accuracy (\% Bias) and precision (\% CV) for the assay standards and QC samples had to be $<15 \%$ (or $<20 \%$ for the lower limit of quantitation $[0.05 \mathrm{ng} / \mathrm{ml}])$. Samples with concentration values $>100 \mathrm{ng} / \mathrm{ml}$ were diluted up to tenfold with blank plasma and re-assayed. Elacestrant plasma concentrations below the lower limit of quantification (LLOQ, $<0.05 \mathrm{ng} /$ $\mathrm{ml}$ ) were set equal to zero for calculations of summary statistics.

\subsection{Statistical Analyses}

\subsubsection{Pharmacokinetic Analyses}

All subjects who received treatment and for whom the pharmacokinetic data were interpretable were included in the pharmacokinetic analyses. Concentration-time data were presented using descriptive statistics. Missing pharmacokinetic parameter data were not imputed. To assess the bioavailability of elacestrant, pharmacokinetic parameters were dose-normalized, logarithmically transformed and evaluated with an analysis of variance (ANOVA, with treatment as the fixed factor and subject as a random factor). Based upon the residual variation from the ANOVA, the ratio of least-square means and corresponding 90\% confidence intervals (CIs) were calculated for subjects in the absolute bioavailability assessment (Study 001 Cohort 4 using area under the curve [AUC]) and for subjects in the relative bioavailability assessment (food effect, Cohort 3, using AUC and $C_{\max }$ ).

To explore the dose proportionality, the geometric means of $C_{\max }$ and AUC were examined against dose. Dose proportionality was assessed using a power model (i.e., Log $(\mathrm{AUC})=\alpha+\beta \times \log ($ dose $)+$ error $)$. An ideal proportional model corresponds to $\beta=1$. Linear dose proportionality was present if the $90 \%$ CI for $\beta$ included 1 .

\subsubsection{Safety Analyses}

All subjects who received at least one dose of study drug (elacestrant or placebo) were included in the safety analyses.
Adverse events were coded using the Medical Dictionary for Regulatory Activities Terminology. Descriptive analyses were used. In Study 001, AEs were recorded as "mild," "moderate" or "severe," and their relationship with the study drug was coded as "none," "remote," "possible," "probable" or "definite." In Study 004, severity of AEs was graded using the Common Terminology Criteria for Adverse Events (CTCAE) 5-point scale.

\subsubsection{Sample Size}

Both Studies 001 and 004 were dose-finding; hence, no prospective calculations of statistical power were made. The sample sizes were selected to provide information on pharmacokinetics, pharmacodynamics, safety, tolerability and MTD of elacestrant.

\section{Results}

\subsection{Subject Disposition and Demographics}

Study 001 was conducted between February 13, 2008, and August 20, 2008. Study 004 was conducted between June 3, 2014, and April 20, 2015. Subject dispositions for Study 001 and Study 004 are shown in Figs. 1 and 2, respectively. In total, 80 subjects received at least one dose of study drug (62 received elacestrant and 18 received placebo). All Study 001 subjects completed the study except for one participant in Cohort 4 of the SAD part who withdrew consent after the first dosing period. In Study 004, 47 subjects were randomized and received at least one dose of study drug in Cohorts 1 through 4 (39 received elacestrant and 8 received placebo), while 13 subjects in Cohort 6 received elacestrant. Among Study 004 subjects, 43 receiving elacestrant and all subjects receiving placebo completed the study; 9 subjects treated with elacestrant at doses $\geq 500 \mathrm{mg}$ daily withdrew because of AEs, as shown in Fig. 2. The demographics of the study populations in Studies 001 and 004 are summarized in Table 1. Subjects in both studies were primarily non-Hispanic or of white ethnicity and were similar in age and BMI.

\subsection{Pharmacokinetic Profile}

\subsubsection{Study 001}

The pharmacokinetic parameters for elacestrant in Study 001 are summarized in Table 2. After a single oral dose under fasted conditions, elacestrant was absorbed rapidly with mean $t_{\max }$ ranging from 1.6 to $3.3 \mathrm{~h}$ (Table 2 and Fig. 3a). Based on geometric mean plasma concentrations, for doses $\geq 10 \mathrm{mg}$, secondary peaks were observed at $4.5-5.0 \mathrm{~h}$ 
Table 1 Demographic characteristics of study subjects

\begin{tabular}{|c|c|c|c|c|}
\hline \multirow[t]{2}{*}{ Characteristic } & \multicolumn{2}{|l|}{ Study 001} & \multicolumn{2}{|l|}{ Study 004} \\
\hline & $\operatorname{SAD}(n=32)$ & $\operatorname{MAD}(n=48)$ & Safety population $(n=52)$ & $\begin{array}{l}\text { Pharmacokinet- } \\
\text { ics population } \\
(n=35)\end{array}$ \\
\hline \multicolumn{5}{|l|}{ Age, years } \\
\hline Mean (range) & $66(57-75)$ & $62(50-75)$ & $62(50-75)$ & $62(50-72)$ \\
\hline \multicolumn{5}{|l|}{ BMI, $\mathrm{kg} / \mathrm{m}^{2}$} \\
\hline Mean (range) & $25.5(20.7-30.0)$ & $24.8(19.5-29.3)$ & $25.2(19.9-29.8)$ & $25.0(19.9-29.8)$ \\
\hline \multicolumn{5}{|l|}{ Race and ethnicity, $n(\%)$} \\
\hline Hispanic/Latino & $0(0 \%)$ & $1(2.1 \%)$ & $1(1.9 \%)$ & $1(2.9 \%)$ \\
\hline Non-Hispanic/Latino & $32(100 \%)$ & $47(97.9 \%)$ & $51(98.1 \%)$ & $34(97.1 \%)$ \\
\hline White & $30(93.8 \%)$ & $47(97.9 \%)$ & $47(90.4 \%)$ & $31(88.6 \%)$ \\
\hline Asian & $1(3.1 \%)$ & $0(0 \%)$ & $1(1.9 \%)$ & $1(2.9 \%)$ \\
\hline American Indian/Alaska Native & $0(0 \%)$ & $0(0 \%)$ & $1(1.9 \%)$ & $1(2.9 \%)$ \\
\hline Mixed & $1(3.1 \%)$ & $1(2.1 \%)$ & $3(5.8 \%)$ & $2(5.7 \%)$ \\
\hline
\end{tabular}

$B M I$ body mass index, $S A D$ single ascending dose, $M A D$ multiple ascending dose

post-dose. The mean $t_{1 / 2}$ with single oral doses up to $200 \mathrm{mg}$ ranged from 27.4 to $32.5 \mathrm{~h}$.

Plasma concentration-time curves plotted after the last dose of elacestrant in the MAD part of Study 001 are shown in Fig. 3b. The mean plasma concentrations of elacestrant were notably higher after the last dose than the first dose, a pattern consistent with accumulation associated with once-daily administration. The geometric means of trough plasma concentrations plateaued around day 6 , suggesting a steady state was achieved after approximately six doses. Steady-state $t_{1 / 2} \mathrm{~s}$ with multiple dosing (31.1- $47.3 \mathrm{~h})$ were higher than those seen with single doses (27.4-32.5 h), possibly related to the longer observation phase following the last dose of the multiple-dose regimen (72 h) compared to the observation phase following single doses $(48 \mathrm{~h})$.

Urine excretion of elacestrant was low after single and multiple dosing, with a maximum of $0.04 \%$ of a given dose recovered in the urine and a renal clearance of $\leq 2.3 \mathrm{ml} / \mathrm{min}$.

Oral elacestrant pharmacokinetic exposure increased slightly more than linear dose proportionality. Comparing the pharmacokinetic parameters across the dose range of $1-200 \mathrm{mg}$ in the SAD part, the slopes $(\beta)$ of the power model equation $[\log (\mathrm{AUC})=\alpha+\beta \cdot \log (\operatorname{dose})]$ for $\mathrm{AUC}_{0-\text { last }}$, $\mathrm{AUC}_{0-\infty}$ and $C_{\max }$ were 1.34 (90\% confidence interval [CI] $1.21-1.47), 1.40$, (90\% CI 1.30-1.50) and 1.21 (90\% CI 1.13-1.28), respectively. Similarly, in the MAD part, comparing the steady-state pharmacokinetic parameters across the dose range of 10-200 mg on Day 7, the slopes $(\beta)$ of the power model equation for $\mathrm{AUC}_{0-\tau}$ and $C_{\max }$ were $1.38(90 \%$ CI 1.29-1.46) and 1.35 (90\% CI 1.27-1.43). The values of $\beta$ were all slightly $>1$, suggesting slightly nonlinear doseproportional increases in elacestrant $C_{\max }$ and AUC.

\subsubsection{Absolute Bioavailability and Food Effect}

The absolute bioavailability of elacestrant was calculated in Study 001 by comparing pharmacokinetic parameters following oral $(100 \mathrm{mg})$ vs. intravenous $(1 \mathrm{mg})$ administration of a single dose in the same cohort of subjects receiving both treatments in the fasted state (Cohort 4 , Fig. 1 and Table 2). An exploratory analysis estimated that the absolute bioavailability of the oral dose of elacestrant using logarithmically transformed ratios of $\mathrm{AUC}_{0-\text { last }}$ and $\mathrm{AUC}_{0-\infty}$ was 0.10 (90\% CI 0.08-0.13) and $0.11(90 \% \mathrm{CI}$ $0.08-0.14$ ), respectively (Supplemental Table S1).

Elacestrant plasma concentrations increased more slowly when administered in the fed state (FDA recommended high-fat, high-calorie meal) compared to the fasted stated (Fig. 1), increasing the mean $t_{\max }$ by about $2 \mathrm{~h}$, from $1.9 \mathrm{~h}$ in fasted subjects to $4.2 \mathrm{~h}$ in fed subjects (Table 2). The high-fat, high-calorie meal also increased relative bioavailability. Comparing the $50 \mathrm{mg}$ single oral dose in fed vs. fasted conditions, the ratio of geometric means for $C_{\max }$ was 2.06 (90\% CI 1.62-2.62), and the ratios for $\mathrm{AUC}_{0-\text { last }}$ and $\mathrm{AUC}_{0-\infty}$ were $1.57(90 \% \mathrm{CI}$ 1.38-1.80) and 1.57 (90\% CI 1.39-1.78), respectively (Supplemental Table S1).

\subsubsection{Study 004}

The geometric mean elacestrant plasma concentrations after 7 days of oral dosing up to $1000 \mathrm{mg}$ daily are plotted 
Table 2 Pharmacokinetic parameters of elacestrant in Study 001 and Study 004

\begin{tabular}{|c|c|c|c|c|c|c|c|}
\hline \multicolumn{8}{|l|}{ Study 001} \\
\hline SAD part ${ }^{\mathrm{a}}$ & $C_{\max }(\mathrm{ng} / \mathrm{ml})$ & $t_{\max }(\mathrm{h})$ & $\mathrm{AUC}_{0-\text { last }}(\mathrm{ng} \cdot \mathrm{h} / \mathrm{ml})$ & $\mathrm{AUC}_{0-\infty}(\mathrm{ng} \cdot \mathrm{h} / \mathrm{ml})$ & $t_{1 / 2}(\mathrm{~h})$ & $\mathrm{CL} / \mathrm{F}(\mathrm{l} / \mathrm{h})$ & $V_{z} / F(1)$ \\
\hline $1 \mathrm{mg} \mathrm{IV}(n=5)$ & $69.8 \pm 30.7$ & $0.04 \pm 0.02$ & $23.9 \pm 3.6$ & $28.0 \pm 5.2$ & $33.4 \pm 6.2$ & $36.8 \pm 7.7^{\mathrm{d}}$ & $1730 \pm 155^{\mathrm{e}}$ \\
\hline $1 \mathrm{mg}(n=2)^{\mathrm{b}}$ & $0.06 \pm 0.02$ & $2.63 \pm 2.65$ & NR & NR & NR & NR & $\mathrm{NR}$ \\
\hline $10 \mathrm{mg}(n=6)$ & $0.7 \pm 0.4$ & $1.92 \pm 1.28$ & $13.1 \pm 9.4$ & $16.8 \pm 11.7$ & $31.9 \pm 8.1$ & $760 \pm 323$ & $33,700 \pm 13,800$ \\
\hline $25 \mathrm{mg}(n=6)$ & $1.8 \pm 0.5$ & $1.64 \pm 1.42$ & $32.2 \pm 15.7$ & $40.6 \pm 21.6$ & $32.5 \pm 6.0$ & $786 \pm 419$ & $34,500 \pm 13,300$ \\
\hline $50 \mathrm{mg}(n=6)$ & $3.4 \pm 0.7$ & $1.92 \pm 2.03$ & $61.3 \pm 11.7$ & $73.3 \pm 13.2$ & $29.1 \pm 3.4$ & $702 \pm 134$ & $29,800 \pm 8910$ \\
\hline $50 \mathrm{mg}$ fed $(n=6)$ & $7.0 \pm 1.5$ & $4.17 \pm 1.33$ & $96.8 \pm 20.0$ & $116 \pm 26.9$ & $28.8 \pm 2.7$ & $451 \pm 111$ & $18,500 \pm 3050$ \\
\hline $100 \mathrm{mg}(n=6)$ & $11.8 \pm 2.0$ & $2.58 \pm 1.72$ & $247 \pm 71.9$ & $294 \pm 80.8$ & $28.4 \pm 3.9$ & $361 \pm 92$ & $14,900 \pm 4920$ \\
\hline $200 \mathrm{mg}(n=6)$ & $31.5 \pm 5.6$ & $3.25 \pm 1.57$ & $649 \pm 183$ & $774 \pm 239$ & $27.4 \pm 3.7$ & $281 \pm 90$ & $10,800 \pm 2860$ \\
\hline MAD part ${ }^{\mathrm{a}}$ & $C_{\max }(\mathrm{ng} / \mathrm{ml})$ & $t_{\max }(\mathrm{h})$ & $\mathrm{AUC}_{0-\tau}(\mathrm{ng} \cdot \mathrm{h} / \mathrm{ml})$ & $R_{\mathrm{ac}}$ & $t_{1 / 2}(\mathrm{~h})$ & $\mathrm{CL}_{\mathrm{ss}} / F(\mathrm{l} / \mathrm{h})$ & $V_{z} / F(1)$ \\
\hline $10 \mathrm{mg} /$ day $(n=7)$ - day 1 & $0.5 \pm 0.1$ & $2.25 \pm 2.24$ & $5.6 \pm 2.0$ & & & & \\
\hline Day 7 & $0.8 \pm 0.2$ & $0.97 \pm 0.27$ & $10.8 \pm 3.7$ & $1.95 \pm 0.29$ & $37.9 \pm 4.7$ & $1020 \pm 347$ & $54,600 \pm 15,100$ \\
\hline $25 \mathrm{mg} /$ day $(n=7)^{\mathrm{c}}$-day 1 & $1.5 \pm 0.5$ & $2.92 \pm 3.50$ & $16.0 \pm 4.1$ & & & & \\
\hline Day 7 & $2.6 \pm 0.8$ & $1.29 \pm 0.47$ & $35.3 \pm 13.9$ & $2.20 \pm 0.68$ & $41.1 \pm 12.7$ & $799 \pm 281$ & $47,100 \pm 21,100$ \\
\hline $50 \mathrm{mg} /$ day $(n=8)$ —day 1 & $4.5 \pm 1.0$ & $1.72 \pm 0.84$ & $45.2 \pm 12.8$ & & & & \\
\hline Day 7 & $5.7 \pm 1.2$ & $2.78 \pm 2.47$ & $82.1 \pm 17.3$ & $1.86 \pm 0.27$ & $31.1 \pm 6.8$ & $634 \pm 139$ & $28,300 \pm 7750$ \\
\hline $100 \mathrm{mg} /$ day $(n=8)$ —day 1 & $10.4 \pm 2.8$ & $3.93 \pm 3.01$ & $122 \pm 55.6$ & & & & \\
\hline Day 7 & $20.5 \pm 7.7$ & $2.50 \pm 1.10$ & $265 \pm 118$ & $2.18 \pm 0.37$ & $35.5 \pm 8.2$ & $437 \pm 166$ & $22,500 \pm 10,100$ \\
\hline $200 \mathrm{mg} /$ day $(n=8)$ — day 1 & $27.3 \pm 6.8$ & $2.94 \pm 1.47$ & $284 \pm 64.8$ & & & & \\
\hline Day 7 & $43.5 \pm 10.8$ & $3.31 \pm 1.58$ & $627 \pm 164$ & $2.22 \pm 0.27$ & $47.3 \pm 24.9$ & $339 \pm 90.4$ & $23,200 \pm 13,200$ \\
\hline \multicolumn{8}{|l|}{ Study 004} \\
\hline $200 \mathrm{mg} /$ day $(n=15)$-day 7 & $51.6 \pm 14.5$ & $3.41 \pm 1.18$ & $695 \pm 200$ & & $38.6 \pm 5.3$ & & \\
\hline $500 \mathrm{mg} /$ day $(n=11)$-day 7 & $209 \pm 72.7$ & $4.46 \pm 1.57$ & $3140 \pm 1195$ & & $37.5 \pm 2.8$ & & \\
\hline $750 \mathrm{mg} /$ day $(n=6)$ —day 7 & $328 \pm 68.6$ & $3.33 \pm 0.52$ & $4810 \pm 1522$ & & $38.6 \pm 4.1$ & & \\
\hline $1000 \mathrm{mg} /$ day $(n=3)$-day 7 & $543 \pm 60.5$ & $4.33 \pm 1.53$ & $8327 \pm 911$ & & $41.6 \pm 5.9$ & & \\
\hline
\end{tabular}

All values reported as arithmetic means \pm standard deviation $(\mathrm{SD})$

$S A D$ single ascending dose, $M A D$ multiple ascending dose, $N R$ no result, $C_{\max }$ maximum concetration, $A U C$ area under the concentration-time curve, $t_{1 / 2}$ half-life, $V_{z} / F$ volume of distribution, $R_{a c}$ accumulation ratio, $C L / F$ clearance, $t_{\max }$ time to reach maximum cocentration, $s s$ steady state ${ }^{a}$ Study drugs were administered in the fasted condition unless otherwise indicated

${ }^{\mathrm{b}}$ One subject was excluded from descriptive statistics due to emesis after dosing

${ }^{c}$ One subject was excluded from descriptive statistics on Day 1 due to emesis after dosing

${ }^{\mathrm{d}} \mathrm{CL}$

${ }^{\mathrm{e}} V_{Z}$

in Fig. 3c. The mean $t_{\max }$ ranged between 3.3 and $4.5 \mathrm{~h}$ and was independent of dose. Trough plasma concentrations, which were assessed from day 5 onward, showed that steady state was already achieved by day 5 (Supplemental Figure S1). Steady-state $t_{1 / 2}$ s ranged from 37.5 to $41.6 \mathrm{~h}$, similar to values observed with multiple oral dosing of 10-200 mg daily in the MAD part of Study 001, and appeared similar regardless of dose.

\subsection{Pharmacodynamic Results and BBB Penetration}

In Cohort 6 of Study 004, ER $\alpha$ occupancy in the brain, pituitary, and uterus was assessed using static and/or dynamic PET scanning. The Vt and SUV in the pituitary could not be corrected for background signal because no suitable non-target reference region was available. Hence, the Vt and SUV in the pituitary without background correction consist partly of receptor-mediated signal and partly of non-specific uptake, leading to an underestimation of receptor occupancy. In contrast to pituitary, individual brain regions showed only very low levels of (non-specific) tracer uptake, both on baseline and postdose PET scans. As a result, ER $\alpha$ occupancy in the brain could not be assessed. Results from static PET scans of the uterus showed $83 \% \mathrm{ER} \alpha$ occupancy in subjects receiving $200 \mathrm{mg}$ elacestrant daily and $92 \%$ in subjects receiving 
Fig. 3 Geometric mean elacestrant plasma concentration values plotted on a logarithmic scale against time since last dose. Individual plots were derived from subjects in: a Study 001, SAD part, following a single dose of elacestrant. b Study 001, MAD part, following the last dose (day 7) of elacestrant. c Study 004, following the last dose (day 7) of elacestrant. ${ }^{\text {a }}$ The elacestrant plasma concentrations for this group were below LLOQ $(<0.05 \mathrm{ng} / \mathrm{ml})$ and therefore these data could not be presented. $S A D$ single ascending dose, $M A D$ multiple ascending dose
A

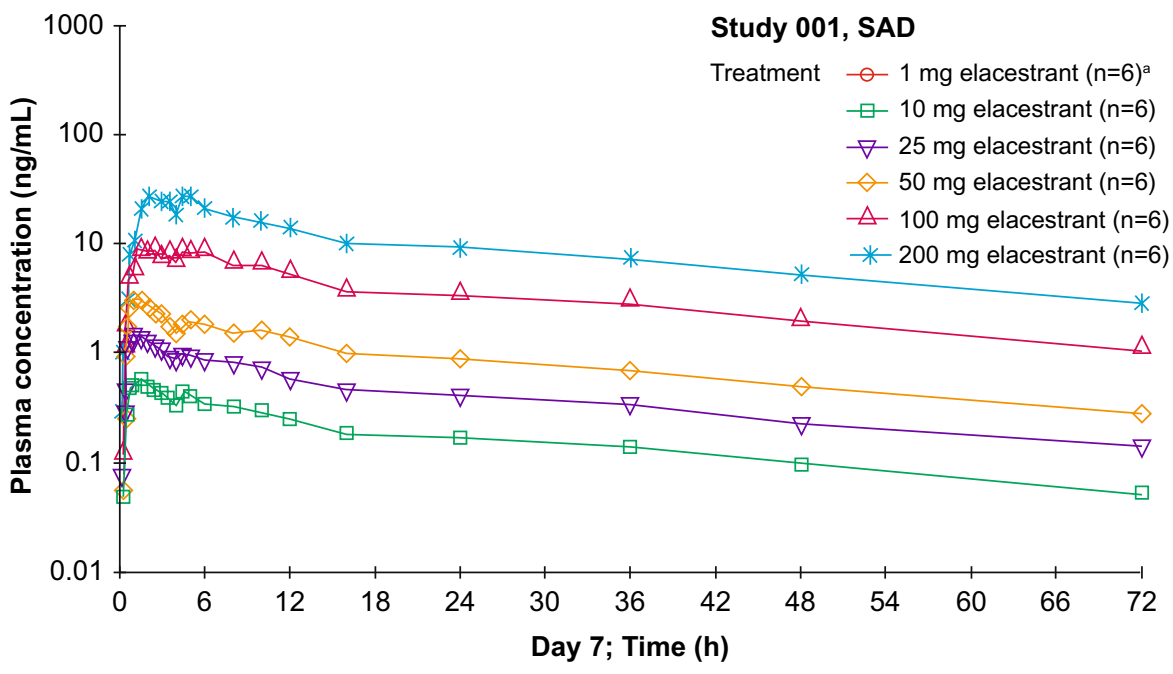

B

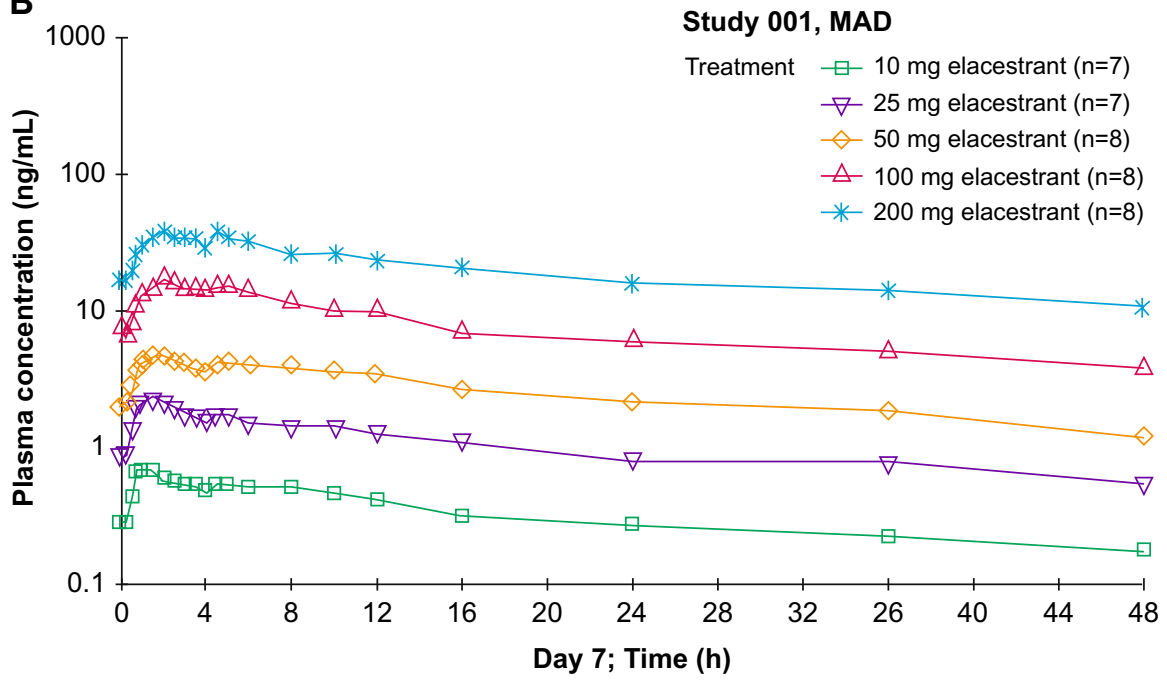

c

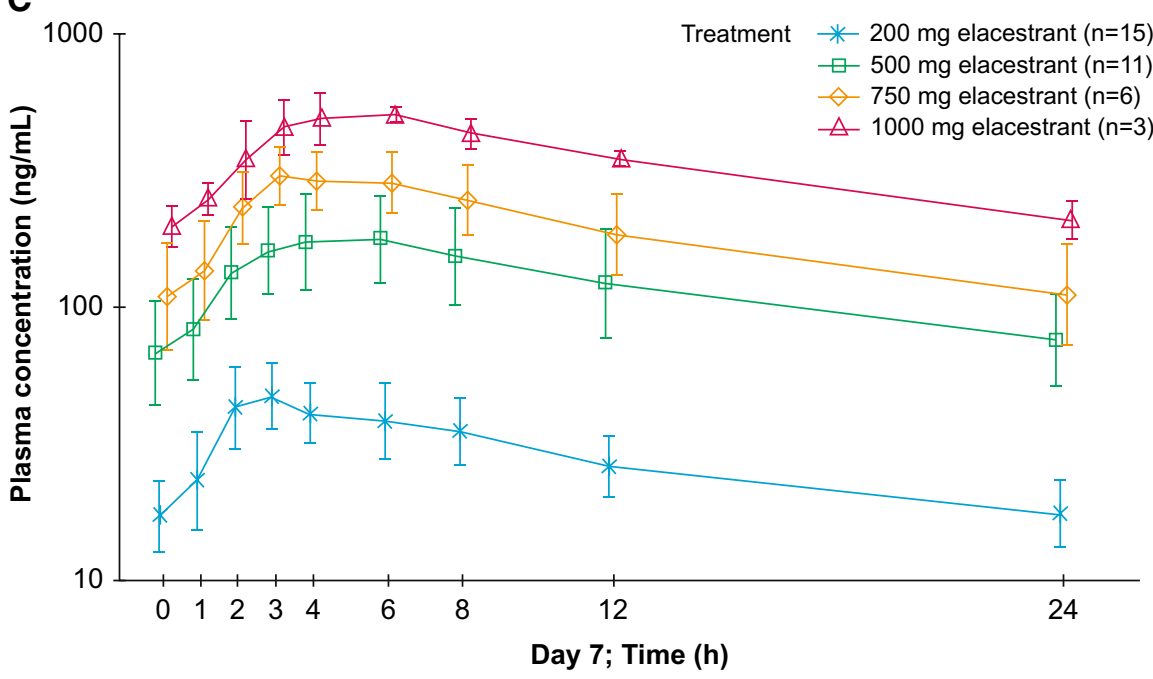


Table 3 Summary of ER $\alpha$ occupancy results from Study 004, Cohort 6

\begin{tabular}{|c|c|c|c|c|c|}
\hline \multirow[t]{3}{*}{ Location } & \multirow[t]{3}{*}{ Scan method ${ }^{\mathrm{a}}$} & \multicolumn{4}{|c|}{ Estimated ER $\alpha$ occupancy (\%) } \\
\hline & & \multicolumn{2}{|c|}{$200 \mathrm{mg}(n=7)$} & \multicolumn{2}{|c|}{$500 \mathrm{mg}(n=6)$} \\
\hline & & $n$ & Mean $( \pm S D)$ & $n$ & Mean $( \pm S D)$ \\
\hline \multirow[t]{2}{*}{ Pituitary } & Static & 3 & $42 \pm 15$ & 4 & $33 \pm 12$ \\
\hline & Dynamic & 1 & 48 & 4 & $36 \pm 9$ \\
\hline Uterus & Static & 3 & $83 \pm 10$ & 4 & $92 \pm 1$ \\
\hline
\end{tabular}

ER estrogen receptor

${ }^{\text {a }}$ Scan performed $4 \mathrm{~h}$ post-dose on Day 6

$500 \mathrm{mg}$ daily (Table 3 and Fig. 4). ER $\alpha$ occupancy in the pituitary (not corrected for background) ranged from 33 to $42 \%$.

The CSF concentrations and the ratio of CSF to plasma concentrations of elacestrant were also assessed in Cohort 6 of Study 004. The median CSF concentrations were 0.0966 and $0.155 \mathrm{ng} / \mathrm{ml}$ for subjects receiving $200 \mathrm{mg}$ and $500 \mathrm{mg}$, respectively, and the corresponding median CSF-to-plasma concentration ratios were $0.205 \%$ and $0.126 \%$, respectively (Supplemental Table S2). A plot of elacestrant concentrations in CSF compared to plasma in individual subjects is shown in Supplemental Figure S2.

\subsection{Safety and Tolerability}

The safety analysis of Study 001 included all subjects who received at least one dose of elacestrant $(n=62)$ or placebo ( $n=18$; Fig. 1$)$. Because each subject participated in two study periods, with different doses of elacestrant or fasted vs. fed conditions in each period, for the purpose of calculating the proportion of subjects with treatmentrelated TEAEs in elacestrant and placebo groups, each subject was counted for the number of periods they had taken at least one dose of study drug $(n=85$ for elacestrant treatment periods and $n=26$ placebo treatment periods; Tables 4, 5). Among all cohorts in Study 001, 33 of 85 (39\%) elacestrant-treated subjects and 7 of 26 (27\%) placebo-treated subjects experienced at least one treatmentrelated TEAE. All were of mild intensity, and none led to study discontinuation. In addition, there were no clinically significant changes in laboratory tests, vital signs, physical examination findings or ECGs, and there were no deaths or other serious AEs. The most common treatment-related

A

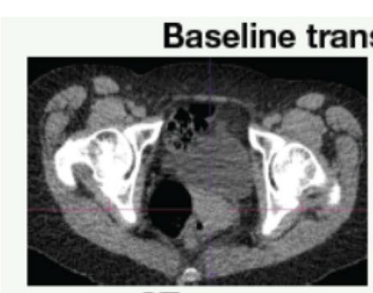

CT scan

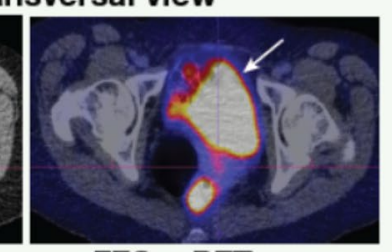

FES - PET scan

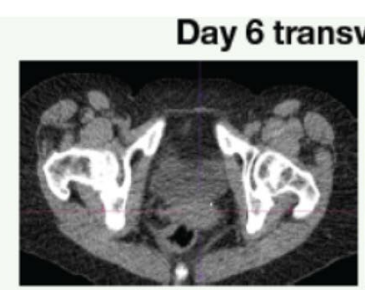

CT scan

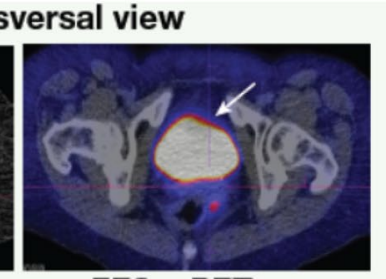

FES - PET scan

\section{B}
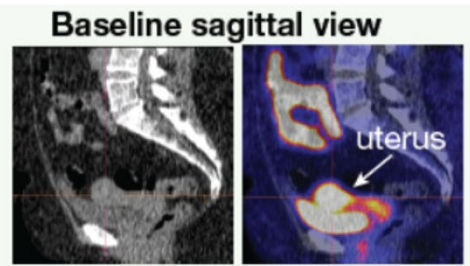

Day 6 sagittal view

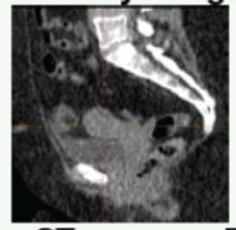

CT scan

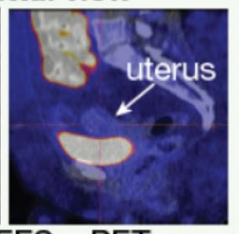

FES - PET scan

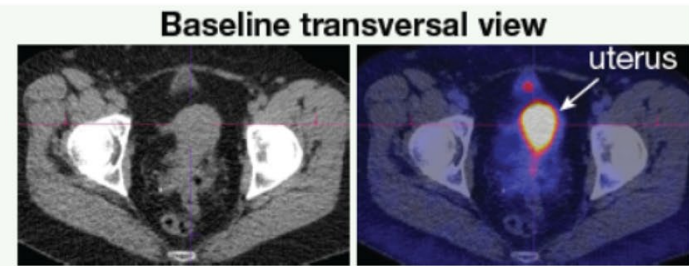

Day 6 transversal view

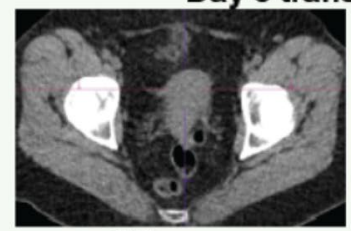

CT scan

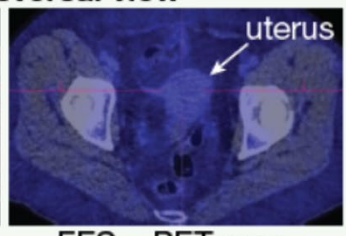

FES - PET scan
Fig. 4 Representative ER $\alpha$ occupancy based on FES-PET imaging of the uterus at baseline and after 6 days of oral elacestrant administration at: a $200 \mathrm{mg}$ and b $500 \mathrm{mg} .{ }^{18} \mathrm{~F}$-FES-PET scans $4 \mathrm{~h}$ post-dose on day 6 in Cohort 6 of Study 004 in a subject 3 from subgroup 1 (elacestrant $200 \mathrm{mg}$ daily) and $\mathbf{b}$ subject 7 from subgroup 2 (elacestrant $500 \mathrm{mg}$ daily) 


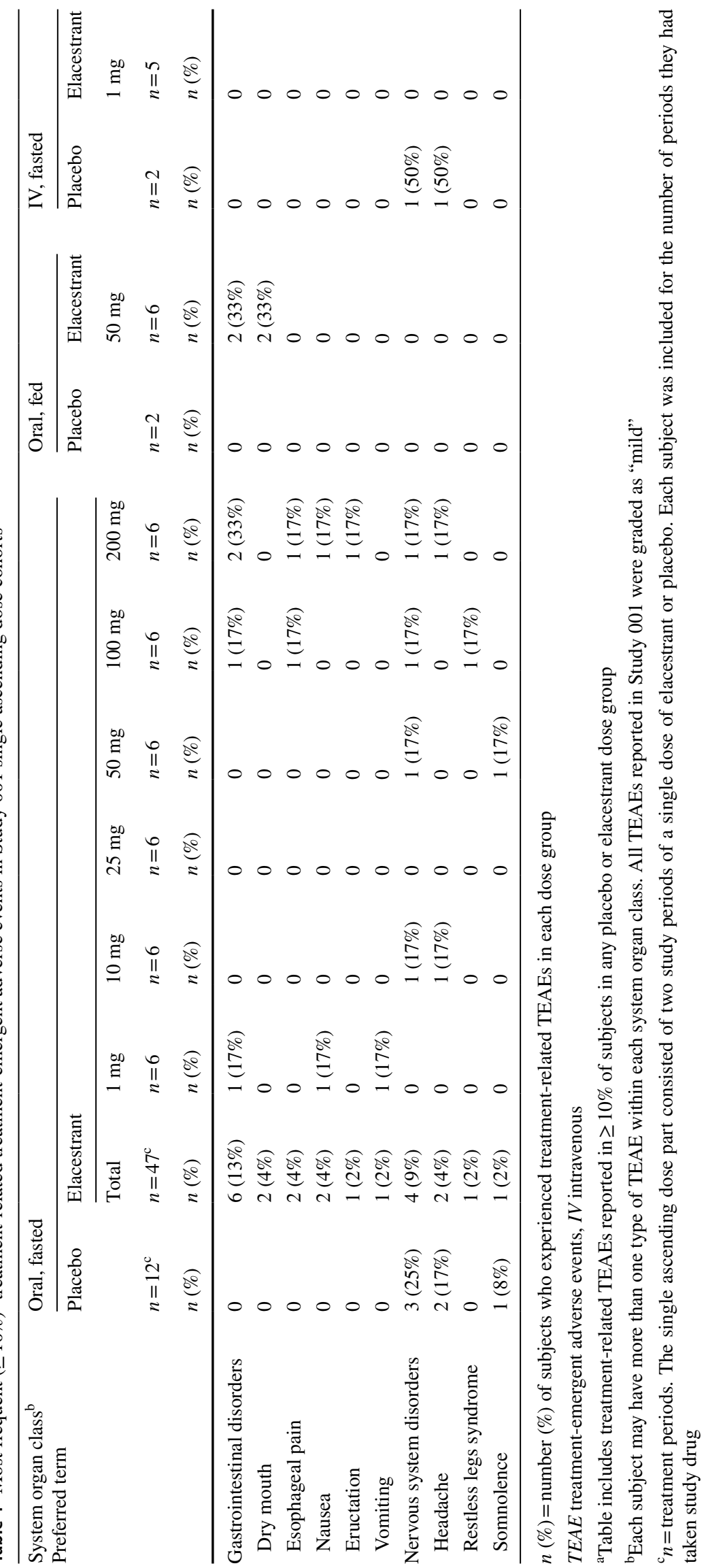


Table 5 Most frequent $(\geq 10 \%)^{\mathrm{a}}$ treatment-related treatmentemergent adverse events in Study 001 multiple ascending dose cohorts

\begin{tabular}{|c|c|c|c|c|c|c|c|}
\hline \multirow[b]{2}{*}{$\begin{array}{l}\text { System organ class } \\
\text { Preferred term }\end{array}$} & \multirow{2}{*}{$\begin{array}{l}\text { Placebo } \\
n=10 \\
n(\%)\end{array}$} & \multicolumn{6}{|c|}{ Elacestrant } \\
\hline & & $\begin{array}{l}n=38 \\
n(\%) \\
\text { Total }\end{array}$ & $\begin{array}{l}n(\%) \\
n=7 \\
10 \mathrm{mg}\end{array}$ & $\begin{array}{l}n(\%) \\
n=7 \\
25 \mathrm{mg}\end{array}$ & $\begin{array}{l}n(\%) \\
n=8 \\
50 \mathrm{mg}\end{array}$ & $\begin{array}{l}n(\%) \\
n=8 \\
100 \mathrm{mg}\end{array}$ & $\begin{array}{l}n(\%) \\
n=8 \\
200 \mathrm{mg}\end{array}$ \\
\hline Gastrointestinal disorders & $1(10 \%)$ & $15(39 \%)$ & 0 & $3(43 \%)$ & $3(38 \%)$ & $5(63 \%)$ & $4(50 \%)$ \\
\hline Dyspepsia & 0 & $7(18 \%)$ & 0 & 0 & $2(25 \%)$ & $3(38 \%)$ & $2(25 \%)$ \\
\hline Nausea & $1(10 \%)$ & $6(16 \%)$ & 0 & $2(29 \%)$ & $1(13 \%)$ & $1(13 \%)$ & $2(25 \%)$ \\
\hline Abdominal pain & 0 & $3(8 \%)$ & 0 & $1(14 \%)$ & 0 & 0 & $2(25 \%)$ \\
\hline Dysphagia & 0 & $2(5 \%)$ & 0 & 0 & 0 & $2(25 \%)$ & 0 \\
\hline Vomiting & 0 & $2(5 \%)$ & 0 & $1(14 \%)$ & $1(13 \%)$ & 0 & 0 \\
\hline Abdominal discomfort & 0 & $1(3 \%)$ & 0 & $1(14 \%)$ & 0 & 0 & 0 \\
\hline Diarrhea & 0 & $1(3 \%)$ & 0 & 0 & $1(13 \%)$ & 0 & 0 \\
\hline Esophageal pain & 0 & $1(3 \%)$ & 0 & $1(14 \%)$ & 0 & 0 & 0 \\
\hline Gastrointestinal pain & 0 & $1(3 \%)$ & 0 & 0 & 0 & 0 & $1(13 \%)$ \\
\hline Nervous system disorders & 0 & $9(24 \%)$ & $1 \quad(14 \%)$ & $2(29 \%)$ & 0 & $2(25 \%)$ & $4(50 \%)$ \\
\hline Headache & 0 & $7(18 \%)$ & $1(14 \%)$ & $2(29 \%)$ & 0 & $1(13 \%)$ & $3(38 \%)$ \\
\hline Dizziness & 0 & $4(11 \%)$ & 0 & $2(29 \%)$ & 0 & 0 & $2(25 \%)$ \\
\hline Paresthesia & 0 & $1(3 \%)$ & 0 & 0 & 0 & $1(13 \%)$ & 0 \\
\hline
\end{tabular}

$T E A E$ treatment-emergent adverse events

${ }^{a}$ Table includes treatment-related TEAEs reported in $\geq 10 \%$ of subjects in any placebo or elacestrant dose group

${ }^{b}$ Each subject may have more than one type of TEAE within each system organ class
TEAEs were in the system organ classes of gastrointestinal disorders (mainly nausea and dyspepsia) and nervous system disorders (mainly headache). In Study 001 SAD part (single-dose elacestrant), among all oral doses tested from 1 to $200 \mathrm{mg}$, and intravenous dose of $1 \mathrm{mg}$, the most common treatment-related TEAEs were dry mouth, esophageal pain, nausea and headache (each 4\%) (Table 4). In Study 001 MAD part, with multiple oral dosing up to $200 \mathrm{mg}$ daily, the most common treatment-related TEAEs reported by $\geq 10 \%$ of subjects included dyspepsia and headache (each 18\%), nausea (16\%) and dizziness (11\%) (Table 5).

The safety analysis of Study 004 included all subjects who received at least one dose of elacestrant $(n=44)$ or placebo ( $n=8$; Fig. 2 ). Among treatment-related TEAEs reported by $\geq 10 \%$ of subjects, the most common were in the system organ class of gastrointestinal disorders $(89 \%$ in elacestrant-treated subjects vs. $38 \%$ in those taking placebo; Table 6). Common gastrointestinal treatment-related TEAEs in elacestrant-treated subjects included nausea (43\%), dyspepsia (36\%), vomiting (32\%), abdominal pain and esophageal pain (each 23\%), salivary hypersecretion (18\%) and diarrhea and dysphagia (each 16\%). Most of these treatment-related gastrointestinal TEAEs were grade 1 or 2 in severity. Treatment-related TEAEs of Grade 3 intensity in elacestrant-treated subjects included two events of esophageal spasm $(750 \mathrm{mg}$ and $1000 \mathrm{mg}$ dose groups), one event of vomiting (500 $\mathrm{mg}$ dose group), one event of esophageal pain (1000 mg dose group) and one event of syncope (1000 mg dose group). There were no treatment-related TEAEs of Grade 4 severity. Treatmentrelated TEAEs in the system organ class of nervous system disorders were reported in $41 \%$ of subjects taking elacestrant vs. $25 \%$ in those taking placebo, with headache being the most common (23\%). Sensation of foreign body (16\% vs. $0 \%$ ), hot flush ( $25 \%$ vs. $13 \%$ ) and hiccups (20\% vs. $0 \%$ ) were also more common in elacestrant-treated subjects. All non-gastrointestinal treatment-related TEAEs occurring in $\geq 10 \%$ of subjects were Grade 1 or 2 in severity.

Most gastrointestinal TEAEs (including nausea, dyspepsia, vomiting and esophageal pain) occurred within $30 \mathrm{~min}$ of dosing, except for diarrhea and abdominal discomfort, which occurred from 1 to $5 \mathrm{~h}$ after dosing. Likewise, the time of onset for sensation of foreign body was generally within 15 min after dosing. Most nervous system TEAEs (including headache) were reported $5 \mathrm{~h}$ after dosing.

There were no deaths or other serious AEs. Nine subjects, all of whom were in elacestrant groups at oral daily doses of $\geq 500 \mathrm{mg}$, were withdrawn from treatment because of 1 or more TEAEs (Table 6), including 3 of 14 subjects in the $500 \mathrm{mg}$ dose group, 2 of 8 subjects in the $750 \mathrm{mg}$ dose group and 4 of 7 subjects in the $1000 \mathrm{mg}$ dose group. Only one of the TEAEs (Grade 1 fatigue), reported by a subject who withdrew, was considered unrelated to treatment, and this subject also had treatment-related gastrointestinal 
Table 6 Most frequent $(\geq 10 \%)^{\mathrm{a}}$ treatment-related treatment-emergent adverse events in Study 004

\begin{tabular}{|c|c|c|c|c|c|c|}
\hline \multirow{4}{*}{$\begin{array}{l}\text { System organ class } \\
\text { Preferred term }\end{array}$} & \multirow{4}{*}{$\begin{array}{l}\text { Placebo } \\
\overline{n=8} \\
n(\%)\end{array}$} & \multicolumn{5}{|c|}{ Elacestrant } \\
\hline & & \multirow{2}{*}{$\frac{\text { Total }}{n=44}$} & \multirow{2}{*}{$\frac{200 \mathrm{mg}}{n=15}$} & \multirow{2}{*}{$\begin{array}{l}500 \mathrm{mg} \\
n=14\end{array}$} & \multirow{2}{*}{$\frac{750 \mathrm{mg}}{n=8}$} & \multirow{2}{*}{$\frac{1000 \mathrm{mg}}{n=7}$} \\
\hline & & & & & & \\
\hline & & $n(\%)$ & $n(\%)$ & $n(\%)$ & $n(\%)$ & $n(\%)$ \\
\hline \multicolumn{7}{|c|}{ Adverse events were grade $1-2$ severity except for five grade 3 TEAEs related to study drug ${ }^{c}$} \\
\hline Total no. of TEAEs related to study drug & 12 & 279 & 62 & 101 & 53 & 63 \\
\hline No. of subjects with at least 1 TEAE related to study drug & $3(38 \%)$ & $42(95 \%)$ & $13(87 \%)$ & $14(100 \%)$ & $8(100 \%)$ & $7(100 \%)$ \\
\hline No. of subjects with TEAEs leading to study discontinuation & 0 & $9(20 \%)$ & 0 & $3(21 \%)$ & $2(25 \%)$ & $4(57 \%)$ \\
\hline Gastrointestinal disorders & $2(25 \%)$ & $39(89 \%)$ & $12(80 \%)$ & $14(100 \%)$ & $7(88 \%)$ & $6(86 \%)$ \\
\hline Nausea & $2(25 \%)$ & $19(43 \%)$ & $5(33 \%)$ & $5(36 \%)$ & $3(38 \%)$ & $6(86 \%)$ \\
\hline Dyspepsia & $1(13 \%)$ & $16(36 \%)$ & $3(20 \%)$ & $7(50 \%)$ & $4(50 \%)$ & $2(29 \%)$ \\
\hline Vomiting & 0 & $14(32 \%)$ & $2(13 \%)$ & $7(50 \%)$ & $2(25 \%)$ & $3(43 \%)$ \\
\hline Abdominal pain & $1(13 \%)$ & $10(23 \%)$ & $4(27 \%)$ & $3(21 \%)$ & $1(13 \%)$ & $2(29 \%)$ \\
\hline Esophageal pain & 0 & $10(23 \%)$ & $2(13 \%)$ & $4(29 \%)$ & $1(13 \%)$ & $3(43 \%)$ \\
\hline Salivary hypersecretion & 0 & $8(18 \%)$ & $2(13 \%)$ & $2(14 \%)$ & $2(25 \%)$ & $2(29 \%)$ \\
\hline Diarrhea & $1(13 \%)$ & $7(16 \%)$ & 0 & $3(21 \%)$ & 0 & $4(57 \%)$ \\
\hline Dysphagia & 0 & $7(16 \%)$ & 0 & $3(21 \%)$ & $4(50 \%)$ & 0 \\
\hline Abdominal distension & 0 & $6(14 \%)$ & $2(13 \%)$ & $1(7 \%)$ & $1(13 \%)$ & $2(29 \%)$ \\
\hline Odynophagia & 0 & $6(14 \%)$ & $2(13 \%)$ & $2(14 \%)$ & 0 & $2(29 \%)$ \\
\hline Abdominal discomfort & 0 & $5(11 \%)$ & $3(20 \%)$ & 0 & $2(25 \%)$ & 0 \\
\hline Flatulence & 0 & $5(11 \%)$ & $2(13 \%)$ & $2(14 \%)$ & $1(13 \%)$ & 0 \\
\hline Nervous system disorders & $2(25 \%)$ & $18(41 \%)$ & $4(27 \%)$ & $6(43 \%)$ & $4(50 \%)$ & $4(57 \%)$ \\
\hline Headache & 0 & $10(23 \%)$ & $3(20 \%)$ & $2(14 \%)$ & $3(38 \%)$ & $2(29 \%)$ \\
\hline Dizziness & $2(25 \%)$ & $5(11 \%)$ & $1(7 \%)$ & $2(14 \%)$ & $1(13 \%)$ & $1(14 \%)$ \\
\hline General disorders and administration site conditions & $1(13 \%)$ & $14(32 \%)$ & $2(13 \%)$ & $4(29 \%)$ & $1(13 \%)$ & $7(100 \%)$ \\
\hline Sensation of foreign body & 0 & $7(16 \%)$ & $2(13 \%)$ & $1(7 \%)$ & 0 & $4(57 \%)$ \\
\hline Vascular disorders & $1(13 \%)$ & $12(27 \%)$ & $3(20 \%)$ & $6(43 \%)$ & $2(25 \%)$ & $1(14 \%)$ \\
\hline Hot flush & $1(13 \%)$ & $11(25 \%)$ & $2(13 \%)$ & $6(43 \%)$ & $2(25 \%)$ & $1(14 \%)$ \\
\hline Respiratory, thoracic and mediastinal disorders & 0 & $10(23 \%)$ & $2(13 \%)$ & $4(29 \%)$ & $2(25 \%)$ & $2(29 \%)$ \\
\hline Hiccups & 0 & $9(20 \%)$ & $1(7 \%)$ & $4(29 \%)$ & $2(25 \%)$ & $2(29 \%)$ \\
\hline Musculoskeletal and connective tissue disorders & $1(13 \%)$ & $6(14 \%)$ & $3(20 \%)$ & $1(7 \%)$ & $1(13 \%)$ & $1(14 \%)$ \\
\hline Myalgia & $1(13 \%)$ & $5(11 \%)$ & $3(20 \%)$ & $1(7 \%)$ & $1(13 \%)$ & 0 \\
\hline
\end{tabular}

TEAE treatment-emergent adverse event

${ }^{a}$ Only treatment-related TEAEs reported in $\geq 10 \%$ of subjects in elacestrant groups $(n=44)$ are individually displayed

${ }^{b}$ Each subject may have more than 1 type of TEAE within each system organ class

${ }^{\mathrm{c}}$ There were 5 grade 3 TEAEs related to study drug, including 1 event of vomiting in the $500 \mathrm{mg}$ dose group; 1 event of esophageal spasm in the $750 \mathrm{mg}$ dose group and 1 event in the $1000 \mathrm{mg}$ dose group; 1 event of esophageal pain in the $1000 \mathrm{mg}$ dose group; and 1 event of syncope in the $1000 \mathrm{mg}$ dose group

TEAEs of Grade 2 and 3 severity. The majority of treatmentrelated TEAEs leading to withdrawal from the study were gastrointestinal TEAEs (Grade 3 for 3 subjects, Grade 2 for 5 subjects and Grade 1 for 1 subject). All TEAEs that led to treatment withdrawal were transient and resolved within $1-5$ days.

An exploratory analysis was performed to evaluate the relationship between elacestrant plasma concentrations and values of corrected QT intervals (QTcF) (Supplemental Figure S3A) and QTcF change from baseline (Supplemental
Figure S3B) from study 004 (200-1000 mg daily for 7 days). The analysis included only data when both elacestrant plasma concentration and QTcF measurements were obtained at the same time point. Slight trends toward longer $\mathrm{QTcF}$ and toward decreased QTcF change from baseline were observed with increasing elacestrant plasma concentrations. Across all elacestrant doses, the maximum QTcF measured was $467 \mathrm{~ms}$, and the maximum QTcF change from baseline was $24 \mathrm{~ms}$, suggesting that oral elacestrant doses of 
up to $1000 \mathrm{mg}$ daily $(2.5 \times$ the anticipated therapeutic dose of $400 \mathrm{mg}$ ) do not adversely affect cardiac repolarization.

Given that the majority of treatment-related TEAEs were gastrointestinal AEs, mostly Grade 1-2 in severity, and that there were no clinically significant changes in laboratory tests, vital signs, physical examination findings or ECGs, deaths or other serious AEs, the investigators determined that the MTD for elacestrant was not reached.

\section{Discussion}

Elacestrant is a novel, nonsteroidal SERD that is currently being evaluated as a potential therapy for ER+ advanced or metastatic breast cancer $[10,21]$. The aims of the two firstin-human phase 1 studies in healthy postmenopausal women presented here were to (1) characterize the pharmacokinetic profile of elacestrant (including bioavailability and food effect) following single and repeated oral dosing ranging from 1 to $1000 \mathrm{mg}$ daily; (2) assess the pharmacodynamic profile of elacestrant via ER $\alpha$ occupancy in the uterus, pituitary and brain based on ${ }^{18}$ F-FES-PET imaging; (3) assess the BBB penetration of elacestrant; (4) evaluate the safety and tolerability across the dose ranges tested; (5) establish the MTD of elacestrant in healthy postmenopausal women.

Elacestrant exhibits rapid oral absorption. Under the fasted condition, mean $t_{\max }$ ranged from 1.0 to $3.9 \mathrm{~h}$ after single and repeated dosing across the 10-200 mg dose range evaluated in Study 001. Plasma concentration profiles of elacestrant exhibited secondary peaks at $4.5-5.0 \mathrm{~h}$ after administration, suggesting enterohepatic circulation of elacestrant and/or metabolites.

For IV administration, the mean systemic clearance ( 36.8 $1 / \mathrm{h}$ [Table 2]) represents approximately $2 / 3$ of the typical liver plasma flow rate (approximately $55 \mathrm{l} / \mathrm{h}$, corresponding to liver blood flow rate of $90 \mathrm{l} / \mathrm{h}$ ). This suggests that the high plasma protein binding of elacestrant (>99\% bound) does not limit the systemic clearance. Similarly, the large mean volume of distribution (1730 liters, [Table 2], approximately $25 \mathrm{l} / \mathrm{kg}$ ) indicates that elacestrant is extensively distributed out of the bloodstream where it binds to the body's tissues. This also suggests that the high plasma protein binding of elacestrant does not limit its distribution. The mean $t_{1 / 2}$ for IV administration was $33.4 \mathrm{~h}$ (Table 2).

A food effect on elacestrant pharmacokinetics was observed. A high-fat breakfast $1 \mathrm{~h}$ before the intake of an oral elacestrant $50 \mathrm{mg}$ capsule delayed the peak plasma concentration by approximately $2 \mathrm{~h}$ and increased the overall $C_{\max }$ by approximately twofold and AUC by 1.6 -fold compared to the fasted state, possibly because of delayed gastric emptying or increased solubility in the fed state. Although the effect of a light meal was not directly evaluated, comparing across studies, the $200 \mathrm{mg}$ dose group in Study 004 (in which an oral elacestrant capsule was administered after a light meal) exhibited only slightly higher $C_{\max }$ (51.6 vs. $43.5 \mathrm{ng} / \mathrm{ml}$ ) and AUC values (695 vs. $627 \mathrm{ng} \cdot \mathrm{h} / \mathrm{ml}$ ) on day 7 compared to the $200 \mathrm{mg}$ group in Study 001 at day 7 (fasting administration). For this same comparison of $200 \mathrm{mg}$ between Study 001 (fasted administration) and Study 004 (light meal), the mean $t_{\max }$ was 3.3 and $3.4 \mathrm{~h}$, respectively, which also indicates a smaller food effect for the light meal than for the high-fat, high-calorie meal.

The $t_{1 / 2}$ of elacestrant ranged from 27.4 to $47.3 \mathrm{~h}$ in both studies. Consistent with the long $t_{1 / 2}$ of elacestrant, steadystate was achieved after 5 or 6 days of once-daily dosing. Elacestrant was absorbed after oral dosing with an absolute bioavailability of $10 \%$. The bioavailability of elacestrant was likely limited by the low, $\mathrm{pH}$-dependent solubility ( $\geq 5 \mathrm{mg}$ / $\mathrm{ml}$ at $\mathrm{pH} 4.5$ and $0.0174 \mathrm{mg} / \mathrm{ml}$ at $\mathrm{pH}$ 6.8) and low permeability of elacestrant, but it is sufficient, along with the other pharmacokinetic characteristics, to allow elacestrant to be administered orally once a day. In comparison, the much lower bioavailability and pre-systemic metabolism of fulvestrant, the only SERD currently marketed, require that a long-acting formulation be administered as two 5-ml intramuscular injections, one in each buttock, at an outpatient clinic every month $[4,22]$.

Systemic exposure (AUC) and $C_{\max }$ increased with dose in a slightly more than dose-proportional manner over the dose range of 25-200 mg in Study 001 and across the 200-1000 mg dose range in Study 004. For Study 001 and Study 004, the power model equation produced slope parameters $(\beta)$ ranging from 1.21 to 1.47 , suggesting slightly nonlinear dose proportionality. To put these slopes into context, these equations predict that a doubling (i.e., a twofold increase) in dose would be expected to increase the $C_{\max }$ or AUC by 2.31 -fold to 2.77 -fold (i.e., $2^{1.21}$-fold to $2^{1.47}$-fold), which are only slightly higher than the expected 2.00 -fold increase with linear dose proportionality. This represents a small deviation from linear dose proportionality that may not be important for dose titration in individual patients. Correspondingly, a reduction in dose from 400 to $300 \mathrm{mg}$, which may occur during treatment with elacestrant, would be expected to decrease the $C_{\max }$ or AUC to 0.706-fold to 0.655 -fold of the original exposure (i.e., $0.75^{1.21}$-fold to $0.75^{1.47}$-fold).

The PET imaging results showed that uterine ER $\alpha$ occupancy was robust, with $>75 \%$ occupancy in the $200 \mathrm{mg}$ dose group and $>90 \%$ in the $500 \mathrm{mg}$ dose group. Thus, higher doses are likely unnecessary to achieve maximum activity. The high ER $\alpha$ occupancy of elacestrant compares favorably with previous data that suggest incomplete ER inhibition in 6 out of $16(38 \%)$ patients treated with fulvestrant at the current standard dose of $500 \mathrm{mg}$ [23]. The robust ER $\alpha$ occupancy may at least in part explain the preliminary antitumor activity demonstrated in preclinical models and observed in 
a phase 1 study in postmenopausal women with ER+ breast cancer $[11-13,17]$.

Elacestrant penetrates the $\mathrm{BBB}$, but concentrations in the CSF were low. Although fulvestrant has been shown to penetrate the brain and hypothalamic tissue in a rat model [24], its ability to cross the BBB has not been reported in humans. In an intracranial MCF-7 MBC mouse model, elacestranttreated animals survived longer than those treated with either fulvestrant or control [12]. In that study, elacestrant concentrations in plasma and in the intracranial tumor were $738 \pm 471 \mathrm{ng} / \mathrm{ml}$ and $462 \pm 105 \mathrm{ng} / \mathrm{ml}$, respectively, suggesting that elacestrant effectively crossed the BBB. In contrast, our clinical study showed very low CSF concentrations of elacestrant. However, given that our attempt to evaluate $\mathrm{ER} \alpha$ occupancy in the brain was unsuccessful, coupled with low CSF concentrations, the potential of elacestrant in the treatment of ER+ MBC that has metastasized to the brain remains unclear. Nevertheless, BBB penetration may be improved in patients with brain metastases where the BBB may be disrupted, and these are the patients most likely to benefit from the treatment.

Elacestrant was well tolerated by most participants with oral doses up to $500 \mathrm{mg}$ daily. At doses $>500 \mathrm{mg}$ daily, gastrointestinal events were poorly tolerated, with some subjects discontinuing treatment because of the events. The most frequently reported TEAEs were nausea, dyspepsia, vomiting and headache. Gastrointestinal TEAEs appear to be dose-related. Some of the upper gastrointestinal TEAEs, such as esophageal spasms and pain, may be related to the rapid release of drug from the capsule formulation and the high number of capsules (up to 7) that had to be taken by the participants. Indeed, gastrointestinal toxicity appeared to be reduced in postmenopausal breast cancer subjects treated with the $400 \mathrm{mg}$ tablet formulation compared to those treated with the $400 \mathrm{mg}$ capsule formulation in Study RAD1901005 [17]. Importantly, there were no deaths, other serious AEs or safety signals based on laboratory, ECG or physical findings. Based on these findings, the MTD was not reached. Although there were more subjects with TEAEs leading to study discontinuation in the $1000 \mathrm{mg}$ dose group, this dose was 2.5-fold higher than the dose currently being studied (400 mg QD) in patients with ER+/HER2- advanced or MBC.

Limitations of both studies (001 and 004) include: (1) these were first-in-human dose-finding studies with small sample size designed to provide information on the pharmacokinetics, pharmacodynamics, safety, tolerability and MTD of elacestrant; (2) studies were carried out in healthy subjects with intact BBB; (3) both studies were conducted with the capsule formulation of elacestrant, which has since been replaced with a tablet formulation.

\section{Conclusions}

Data from 2 phase 1 studies in healthy postmenopausal subjects demonstrate that elacestrant is safe and well tolerated at oral doses up to $500 \mathrm{mg}$ per day. Robust ER $\alpha$ occupancy (75-90\%) was observed at doses of 200-500 mg daily. The bioavailability and long $\mathrm{t}_{1 / 2}$ of elacestrant support a oncedaily oral dosing strategy. Collectively, the pharmacokinetic profile of elacestrant, ER $\alpha$ occupancy and safety data in the dose range tested support the $400 \mathrm{mg}$ daily oral dosing strategy selected for further evaluation in an ongoing phase 3 clinical trial (NCT03778931) in postmenopausal women and men with ER+/HER2- advanced or metastatic breast cancer $[10,21]$.

Acknowledgements The authors thank Phillips Gilmore Oncology Communications, Inc., for professional assistance with manuscript preparation, which was funded by Radius Health, Inc.

\section{Compliance with Ethical Standards}

Funding This work was supported by Radius Health, Inc., on behalf of its wholly owned subsidiary, Radius Pharmaceuticals, Inc.

Competing interests EFJDV: received payment from Radius Health, Inc., for the execution and analysis of the PET scans. AWJMG: no competing interest. YW, ST and MGC are employees and stockholders of Radius Health, Inc.

Ethics approval The clinical study protocols and informed consent forms were reviewed and approved by an independent ethics committee, and all subjects provided written informed consent. Both studies were conducted in accordance with the principles of the Declaration of Helsinki and in compliance with the International Conference on Harmonisation (ICH) E6 Guideline for Good Clinical Practice (GCP) (Committee for Proprietary Medicinal Products (CPMP) guideline CPMP/ICH/135/95), and with the EU CTD: Directive 2001/20/EC.

Informed consent All subjects were informed verbally and in writing of the objectives, procedures and risks of study participation including possible side effects and potential interactions. All participants signed the informed consent form before starting the studies.

Availability of data and materials Data that underlie the results reported in a published article may be requested for further research 6 months after completion of FDA or EMA regulatory review of a marketing application or 18 months after trial completion (whichever is latest and/or if not associated with a marketing application). Radius will review requests individually to determine whether (1) the requests are legitimate and relevant and meet sound scientific research principles and (2) are within the scope of the participants' informed consent. Prior to making data available, requestors will be required to agree in writing to certain obligations, including without limitation, compliance with applicable privacy and other laws and regulations. Proposals should be directed to info@radiuspharm.com.

Open Access This article is licensed under a Creative Commons Attribution-NonCommercial 4.0 International License, which permits any non-commercial use, sharing, adaptation, distribution and reproduction in any medium or format, as long as you give appropriate credit to the original author(s) and the source, provide a link to the Creative 
Commons licence, and indicate if changes were made. The images or other third party material in this article are included in the article's Creative Commons licence, unless indicated otherwise in a credit line to the material. If material is not included in the article's Creative Commons licence and your intended use is not permitted by statutory regulation or exceeds the permitted use, you will need to obtain permission directly from the copyright holder. To view a copy of this licence, visit http://creativecommons.org/licenses/by-nc/4.0/.

\section{References}

1. Siegel RL, Miller KD, Jemal A. Cancer statistics, 2019. CA Cancer J Clin. 2019;69(1):7-34. https://doi.org/10.3322/caac.21551.

2. Huang HJ, Neven P, Drijkoningen M, Paridaens R, Wildiers $\mathrm{H}$, Van Limbergen E, et al. Association between tumour characteristics and HER-2/neu by immunohistochemistry in 1362 women with primary operable breast cancer. J Clin Pathol. 2005;58(6):611-6. https://doi.org/10.1136/jcp.2004.022772.

3. National Comprehensive Cancer N. NCCN Clinical Practice Guidelines in Oncology (NCCN Guidelines): Breast Cancer Version 2.2020-Feb 9, 2020.

4. FASLODEX [prescribing information]. Wilmington, DE: AstraZeneca Pharmaceuticals LP; 2019.

5. Robertson JFR, Bondarenko IM, Trishkina E, Dvorkin M, Panasci $\mathrm{L}$, Manikhas A, et al. Fulvestrant $500 \mathrm{mg}$ versus anastrozole 1 $\mathrm{mg}$ for hormone receptor-positive advanced breast cancer (FALCON): an international, randomised, double-blind, phase 3 trial. Lancet. 2016;388:2997-3005. https://doi.org/10.1016/S0140 -6736(16)32389-3.

6. Cristofanilli M, Turner NC, Bondarenko I, Ro J, Im SA, Masuda N, et al. Fulvestrant plus palbociclib versus fulvestrant plus placebo for treatment of hormone-receptor-positive, HER2negative metastatic breast cancer that progressed on previous endocrine therapy (PALOMA-3): final analysis of the multicentre, double-blind, phase 3 randomised controlled trial. Lancet Oncol. 2016;17(4):425-39. https://doi.org/10.1016/S1470 -2045(15)00613-0.

7. Slamon DJ, Neven P, Chia S, Fasching PA, De Laurentiis M, Im $\mathrm{SA}$, et al. Phase III randomized study of ribociclib and fulvestrant in hormone receptor-positive, human epidermal growth factor receptor 2-negative advanced breast cancer: MONALEESA-3. J Clin Oncol. 2018;36(24):2465-72. https://doi.org/10.1200/ JCO.2018.78.9909.

8. Sledge GW, Toi M, Neven P, Sohn J, Inoue K, Pivot X, et al. MONARCH 2: abemaciclib in combination with fulvestrant in women with HR+/HER2-advanced breast cancer who had progressed while receiving endocrine therapy. J Clin Oncol. 2017;35(25):2875-84. https://doi.org/10.1200/JCO.2017.73.7585.

9. Turner NC, Slamon DJ, Ro J, Bondarenko I, Im S-A, Masuda N, et al. Overall survival with palbociclib and fulvestrant in advanced breast cancer. N Engl J Med. 2018;379(20):1926-36. https://doi. org/10.1056/NEJMoa1810527.

10. Bardia A, Aftimos P, Bihani T, Anderson-Villaluz AT, Jung J, Conlan MG, et al. EMERALD: phase III trial of elacestrant (RAD1901) vs endocrine therapy for previously treated ER+ advanced breast cancer. Future Oncol. 2019;15(28):3209-18. https://doi.org/10.2217/fon-2019-0370.

11. Bihani T, Patel HK, Arlt H, Tao N, Jiang H, Brown JL, et al. Elacestrant (RAD1901), a selective estrogen receptor degrader
(SERD), has antitumor acvity in multiple ER(+) breast cancer patient-derived xenograft models. Clin Cancer Res. 2017;23(16):4793-804. https://doi.org/10.1158/1078-0432. CCR-16-2561.

12. Garner F, Shomali M, Paquin D, Lyttle CR, Hattersley G. RAD1901: a novel, orally bioavailable selective estrogen receptor degrader that demonstrates antitumor activity in breast cancer xenograft models. Anticancer Drugs. 2015;26(9):948-56. https:// doi.org/10.1097/cad.0000000000000271.

13. Wardell SE, Nelson ER, Chao CA, Alley HM, McDonnell DP. Evaluation of the pharmacological activities of RAD1901, a selective estrogen receptor degrader. Endocr Relat Cancer. 2015;22(5):713-24. https://doi.org/10.1530/erc-15-0287.

14. Arlt H, Garner F, Bihani T. Elacestrant (RAD1901) demonstrates anti-tumor activity in a fulvestrant-resistant PDX model [abstract]. In: Proceedings of 2017 San Antonio breast cancer symposium; 5-9 Dec 2017; San Antonio, TX. Cancer Res. 2018;78(4 Suppl):P4-04-17.

15. Patel H, Tao N, Arlt H, Bihani T. Anti-tumor activity of elacestrant (RAD1901) in models harboring ESR1 mutations resistant to standard of care therapies [abstract]. In: Proceedings of the 2018 San Antonio breast cancer symposium; 4-8 Dec 2018; San Antonio, TX. Cancer Res. 2019;74 (4 Suppl):P6-20-08.

16. Patel HK, Tao N, Lee KM, et al. Elacestrant (RAD1901) exhibits anti-tumor activity in multiple ER+ breast cancer models resistant to CDK4/6 inhibitors. Breast Cancer Res. 2019;21(1):146. https ://doi.org/10.1186/s13058-019-1230-0.

17. Kaklamani V, Bardia A, Wilks S, Weise A, Richards D, Harb W, et al. Final analysis of phase 1 study of elacestrant (RAD1901), a novel selective estrogen receptor degrader (SERD), in estrogen receptor positive $(E R+)$, human epidermal growth factor receptor 2 negative (HER2-) advanced breast cancer. Cancer Res. 2020;80(4 Suppl):PD7-07.

18. FDA. Guidance for industry: food-effect bioavailability and fed bioequivalence studies. Rockville: Food and Drug Administration; 2002.

19. Römer J, Steinbach J, Kasch H. Studies on the synthesis of 16-alpha-[18F]fluoroestradiol. Appl Radiat Isot. 1996;47:395-9.

20. Khayum MA, de Vries EFJ, Glaudemans AWJM, Dierckx RAJO, Doorduin J. In vivo imaging of brain estrogen receptors in rats: a $16 \alpha-18$ F-fluoro- $17 \beta$-estradiol PET study. J Nucl Med. 2014;55:481-7.

21. ClinicalTrials.gov. Phase 3 trial of elacestrant vs. standard of care for the treatment of patients with ER+/HER2- advanced breast cancer (EMERALD). https://clinicaltrials.gov/ct2/show/NCT03 778931. Accessed 12 Sept 2019.

22. Robertson JF, Harrison M. Fulvestrant: pharmacokinetics and pharmacology. Br J Cancer. 2004;90(Suppl 1):S7-10. https://doi. org/10.1038/sj.bjc.6601630.

23. van Kruchten M, de Vries EG, Glaudemans AW, van Lanschot MC, van Faassen M, Kema IP, et al. Measuring residual estrogen receptor availability during fulvestrant therapy in patients with metastatic breast cancer. Cancer Discov. 2015;5(1):72-81. https ://doi.org/10.1158/2159-8290.Cd-14-0697.

24. Alfinito PD, Chen X, Atherton J, Cosmi S, Deecher DC. ICI 182,780 penetrates brain and hypothalamic tissue and has functional effects in the brain after systemic dosing. Endocrinology. 2008;149(10):5219-26. https://doi.org/10.1210/en.2008-0532. 